Соленое Займище, Астраханская область (РФ, 400002, Волгоградская обл., г. Волгоград, пр. Университетский, д. 26) https://www.orcid-ru.org/ 0000-0002-6486-9210, т. +7 (8442) 41-12-20, +7 (902) 387-29-42, E-mail: borisenivan@yandex.ru

Мезникова Марина Викторовна, кандидат технических наук, преподаватель кафедры «Безопасность жизнедеятельности» ФГБОУ ВО Волгоградский государственный аграрный университет, (РФ, 400002, Волгоградская обл., г. Волгоград, пр. Университетский, д. 26), https:/www.orcid-ru.org/ 0000-0002-9384-7766, т.+7 (8442) 41-15-18,+7(960)883-09-50, E-mail: marina_roxette@mail.ru

Улыбина Екатерина Ивановна, преподаватель ГБПОУ «Себряковский технологический техникум» (РФ, 403345, Волгоградская обл., г. Михайловка, ул. Коммуны д. 146 a), https://www.orcidru.org/ 0000-0002-3523-4478 т. +7(905)434-39-16,

E-mail: ulibina.ekat@yandex.ru

\title{
THEORETICAL AND EXPERIMENTAL METHOD FOR PREDICTION WEAR OF CHISEL BITS
}

\author{
D.S. Gapich, V. A. Motorin, R.N. Oleinikov \\ Volgograd State Agrarian University, Volgograd
}

Received 30.10.2020

Submitted 25.05.2021

\section{The research was conducted as a part of the grant of the President of the Russian Federation MK-2870.2019.8}

\section{Summary}

Consider modeling the process of wear of the working parts of chisel plow based on the gradual wear of the working parts: the first stage is associated with the formation of the geometry of the bow that provides minimal resistance when moving the working part to the processed material; the second stage is a translational displacement of the obtained cross-section to ultimate limit state. The equation of the wear curve of the working parts of a chisel plow is obtained.

\begin{abstract}
Introduction. The main agricultural tool used in the non-shaft method of processing is chisel plows, which can provide deep loosening of the soil. One of the most heavily loaded parts of the chisel plow are the working parts, since the technical resource of the entire tillage unit depends on them. Premature failure is associated with the process of abrasive wear that occurs when the chisel plow bit interacts with solid soil particles. Reducing the cost of tillage during chiseling and planning the technical resource of agricultural tool parts in real working conditions are topical issues of crop cultivation.

Materials and methods. Two samples of chisel plow chisel were examined. The first sample is made of high-strength cast iron of the HF 50 brand (composition in \%: $3.39 \mathrm{C} ; 0.51 \mathrm{Mn} ; 2.71 \mathrm{Si} ; 0.041 \mathrm{~S}$ ), the second is made of steel 45 , hardened according to the mode. The main laboratory and field studies were carried out at the Educational research and production center «Gornaya Polyana», on classic light chestnut (Calcic Kastanozem) soils with a resistivity coefficient of 7-12, a low content of organic residues (humus-1.5-2.5\%), and a humidity of $8-10 \%$. Tests of the working parts of the chisel plow were carried out to the limit of wear. The General test conditions on average correspond to the typical relief of the Volgograd region, the type and physical and mechanical properties of the soil and other criteria for the quality of work. Both types of test bits were simultaneously installed on one unit, with the possibility of their distribution across the housings depending on the degree of load, to achieve the most equal working conditions. Results and conclusions. To assess the end of the service life of experimental chisels, the maximum wear of the linear size of the bow was used, with a decrease in the linear indicator in this section, the wear was transferred to the rack of the chisel plow, due to which the working part is attached to the frame of the tillage tool. Modeling the wear process of chisel plow bits becomes difficult, since depending on the selected field, and often within the same field, the soil has different physical and mechanical properties and granulometric composition. They differ depending on
\end{abstract}


the type of soil and the amount of abrasive particles recorded in them, the number of which can vary from 37 to $77 \%$, as well as the diverse selection of materials currently presented, from which the working parts of chisel plows are made. Experimental studies have shown that, regardless of the material from which chisel bits are made, the patterns of formation of the geometry of wear of working surfaces obey a single logic. The first stage is the formation of the geometry of the nose, the second stage is the translational movement of the resulting section of the cutting part. The maximum technical life of the chisel plow bit is controlled by the linear wear of the section I-I. Knowing the value of the limit wear, at any stage of work and operating time, we determine the linear size of the cross-section I-I and determine the technical resource of the chisel plow bit from the similarity condition.

Key words: model of wear of rigid parts, cutting tools for soil development, wear of working parts of tillage machines, cast iron with spherical graphite, ledeburite, graphite eutectic.

Citation. Gapich D. S., Motorin V. A., Oleinikov R. N. Theoretical and experimental method for prediction wear of chisel bits. Proc. of the Lower Volga Agro-University Comp. 2021. 2(62). 347-356 (in Russian). DOI: 10.32786/2071-9485-2021-02-36.

Author's contribution. All authors of this research paper have directly participated in the planning, execution, or analysis of this study. All authors of this paper have read and approved the final version submitted.

Conflict of interest. The authors declare no conflict of interest.

УДК 621.785 .5

\title{
ТЕОРЕТИКО-ЭКСПЕРИМЕНТАЛЬНЫЙ СПОСОБ ПРОГНОЗИРОВАНИЯ ИЗНОСА ДОЛОТ ЧИЗЕЛЯ
}

\author{
Д. С. Гапич, доктор технических наук, дочент \\ В. А. Моторин, кандидат технических наук, дочент \\ Р. Н. Олейников, аспирант
}

Волгоградский государственный аграрный университет, г. Волгоград

Дата поступления в редакцию 30.10 .2020

Дата принятия к печати 25.05.2021

\section{Работа выполнена в рамках гранта Президента Российской Федерации МК-2870.2019.8.}

Актуальность. Главным сельскохозяйственным орудием, использующимся при безотвальном способе обработки, являются чизельные плуги, способные обеспечить глубокое рыхление почвы. Наиболее тяжелонагруженными деталями чизельного плуга являются рабочие органы, так как технический ресурс всего почвообрабатывающего агрегата зависит именно от них. Преждевременный отказ связан с процессом абразивного износа, происходящего при взаимодействии долот чизельного плуга с твердыми частицами почвы. Снижение себестоимости обработки почвы при чизелевании и вопросы планирования технического ресурса деталей сельскохозяйственного орудия в реальных условиях работы являются актуальными вопросами возделывания культур. Материалы и методы. Исследовались два образца долот чизельного плуга. Первый образец изготовлен из высокопрочного чугуна марки ВЧ 50 (состав в \%: 3,39 С; $0,51 \mathrm{Mn} ; 2,71 \mathrm{Si} ; 0,041 \mathrm{~S}$ ), второй - из стали 45, закаленной по режиму. Проведение основных лабораторно-полевых исследований осуществлялось в УНЦП «Горная Поляна» на классических светло-каштановых (Calcic Kastanozem) почвах, имеющих коэффициент удельного сопротивления 7-12, низкое содержание органических остатков (гумус - 1,5-2,5\%), влажность $-8-10$ \%. Испытания рабочих органов чизельного плуга проводились до предельного износа. Общие условия проведения испытаний по типу и физико-механическим свойствам почвы и другим критериям качества работы в среднем соответствуют типовому рельефу Волгоградской области. Оба вида испытуемых долот были одновременно установлены на один агрегат с возможностью их распределения по корпусам в зависимости от степени нагрузки для достижения наиболее равных условий работы. Результаты и выводы. Экспериментальные исследования показали, независимо от материала, из которого изготовлены долота чизельных орудий, картины формирования геометрии износа рабочих поверхностей подчиняются единой логике. Первый этап - формирование геометрии носовой части, второй этап - поступательное перемещение полученного сечения режущей части. Предельный технический ресурс долота чизельного плуга 
контролируется линейным износом сечения I-I. Зная значение предельного износа, на любом этапе работ и наработке определяем линейный размер сечения I-I и из условия подобия определяем технический ресурс долота чизельного плуга.

Ключевые слова: модель изнашивания жёстких тел, режущчие инструменты для разработки грунтов, износ рабочих органов почвообрабатывающих машин, ледебурит, графитовая эвтектика.

Цитирование. Гапич Д. С., Моторин В. А., Олейников Р. Н. Теоретико-экспериментальный способ прогнозирования износа долот чизеля. Известия НВ АУК. 2021. 2(62). 347-356. DOI: 10.32786/2071-9485-2021-02-36.

Авторский вклад. Все авторы настоящего исследования принимали непосредственное участие в планировании, выполнении или анализе данного исследования. Все авторы настоящей статьи ознакомились и одобрили представленный окончательный вариант.

Конфликт интересов. Авторы заявляют об отсутствии конфликта интересов.

Введение. В борьбе с ветровой эрозией почв лучшим видом обработки почвы является безотвальная обработка. Данная обработка внедрена во многих регионах России, результаты доказали свою эффективность. Урожайность сельскохозяйственных культур повышается на 2-3 ц с одного гектара в сравнении с использованием отвальной обработки. Основным средством реализации безотвального способа обработки является чизельный плуг, который способен рыхлить почву до 1,2 м $[1,2,9,13,14]$. Однако рыхление на таких глубинах создает тяжелые режимы работы для деталей чизельного плуга в целом, и в частности рабочих органов (долот), которые и определяют технический ресурс всего почвообрабатывающего агрегата $[3-5,7,8,10,11]$. Отказ наступает в связи с процессом микроцарапания твердыми частицами почвы, которые жестко закреплены в матрице, и их твердость, по Виккерсу, достигает 8-11 ГПа $[6,12,15]$.

Значительное увеличение себестоимости обработки почвы при чизелевании и обострение актуальных вопросов планирования технического ресурса деталей сельскохозяйственного орудия в реальных условиях работы являются следствием частой замены долот чизельного плуга, затрат человеко-часов трудозатрат на восстановление работоспособности агрегата в полевых условиях, повышенных расходов горюче-смазочных материалов из-за возрастания сопротивления на крюке при затуплении лезвийной части.

Цель работы - смоделировать износ рабочих органов чизельного плуга с прогнозированием ресурса.

Материалы и методы. Объектами исследования являлись два образца долот чизельного плуга. Первый образец изготовлен из высокопрочного чугуна марки ВЧ 50 (состав в \%: 3,38 C; 0,52 Mn; 2,71 Si; 0,042 S), второй - из стали 45, закаленной по режиму. Режимы термообработки долот чизельного плуга приведены в таблице 1.

Таблица 1 - Режимы термической обработки экспериментальных образцов долот чизельного плуга

Table 1 - Materials of experimental samples of working bodies and their heat treatment modes

\begin{tabular}{|l|l|}
\hline \multicolumn{2}{|c|}{ Режимы термообработки / Modes of heat treatment } \\
\hline \multicolumn{1}{|c|}{ Материал / Material } & \multicolumn{1}{|c|}{ Режим термообработки / Heat treatment mode } \\
\hline $\begin{array}{l}\text { № 1. Чугун ВЧ50 } \\
\text { No. 1. Cast iron VCH50 с }\end{array}$ & $\begin{array}{l}\text { Воздействие электрической дуги неплавящимся электродом сплав- } \\
\text { лением поверхности / Exposure to an electric arc by a non-melting elec- } \\
\text { trode with surface reflow }\end{array}$ \\
\hline $\begin{array}{l}\text { № 2. Сталь 45 } \\
\text { o. 2. Steel 45 }\end{array}$ & $\begin{array}{l}\text { Tемпература нормализация } \mathrm{t}=880^{\circ} \mathrm{C} \text { в течение } \tau=2 \text { час., с охлажде- } \\
\text { нием на открытом воздухе / Temperature normalization } \mathrm{t}=880^{\circ} \mathrm{C} \text { for } \tau \\
=2 \text { hours, with outdoor cooling }\end{array}$ \\
\hline
\end{tabular}


Поверхностно упрочненный слой в виде отбеленного ледебурита, который получен на чугуне в образце № 1 имеет микротвердость $\mathrm{H}_{50}=10105 \pm 1403$ МПа.

Наиболее распространенная при изготовлении рабочих органов чизельных орудий марка сталь 45 в образце № 2 имеет характерную для закаленного состояния твердость - НВ $560 \pm 2,1$.

Проведение основных лабораторно-полевых исследований осуществлялось в УНЦП «Горная Поляна» на классических светло-каштановых (Calcic Kastanozem) почвах, имеющих коэффициент удельного сопротивления 7-12, низкое содержание органических остатков (гумус - 1,5-2,5 \%), влажность - 8-10\%. Испытания рабочих органов чизельного плуга проводились до предельного износа (рисунок 1). Общие условия проведения испытаний по типу и физико-механическим свойствам почвы и другим критериям качества работы в среднем соответствуют типовому рельефу Волгоградской области.

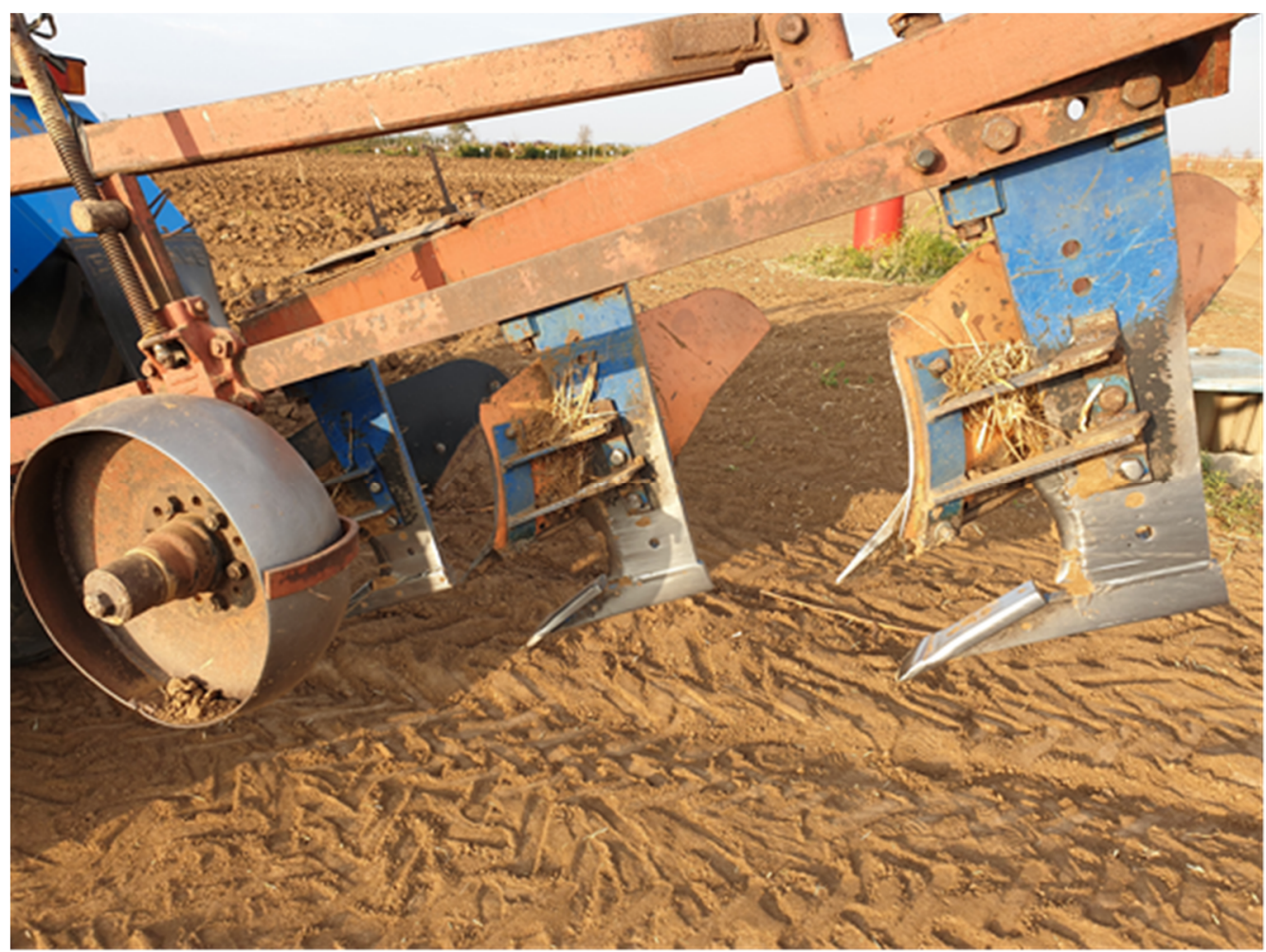

Рисунок 1 - Процесс замера линейных размеров износа долот чизельного плуга по сечениям

Figure 1 - the process of measuring the linear wear dimensions of chisel plow bits by cross-sections

Для достижения наиболее качественных результатов испытаний необходимо обеспечить эксплуатацию опытных серийных и экспериментальных лемехов при максимально возможных равных условиях. Оптимальным решением данной задачи является одновременная установка обоих видов испытуемых долот на один агрегат с возможностью их распределения по корпусам в зависимости от степени нагрузки для достижения наиболее равных условий работы.

В результате проведения полевых испытаний измерялись линейные размеры по контрольным сечениям, расположенным на долоте чизельного плуга в сечении носка вдоль вертикальной оси, а также по ширине (рисунок 2). Ежедневно в конце смены записывались размеры по каждому контрольному сечению, взвешивались образцы. 


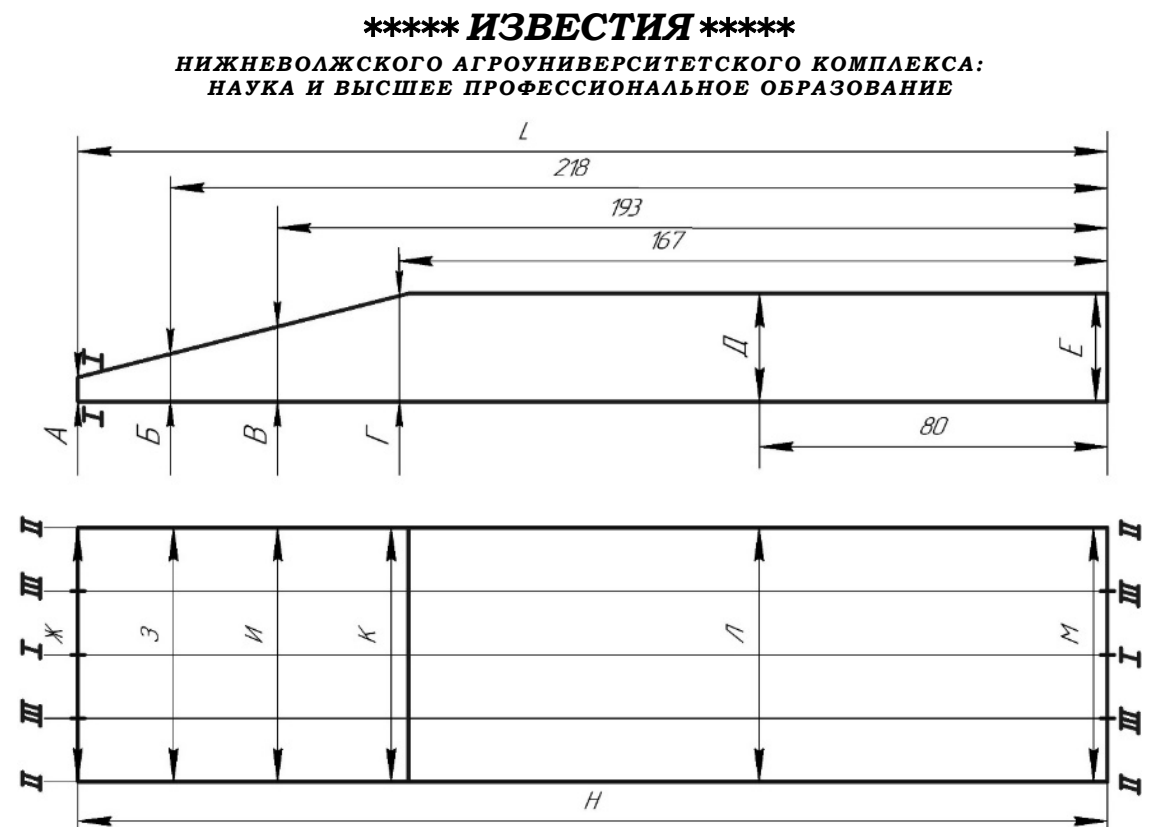

Рисунок 2 - Расположение контрольных сечений долота

Figure 2 - location of the control sections of the bit

Результаты и обсуждение. Для оценки окончания ресурса у экспериментальных долот являлся предельный износ линейного размера носовой части (рисунок 3) с уменьшением линейного показателя в данном сечении износ переходил на стойку чизельного плуга, за счет которой происходит крепление рабочего органа к раме почвообрабатывающего орудия.

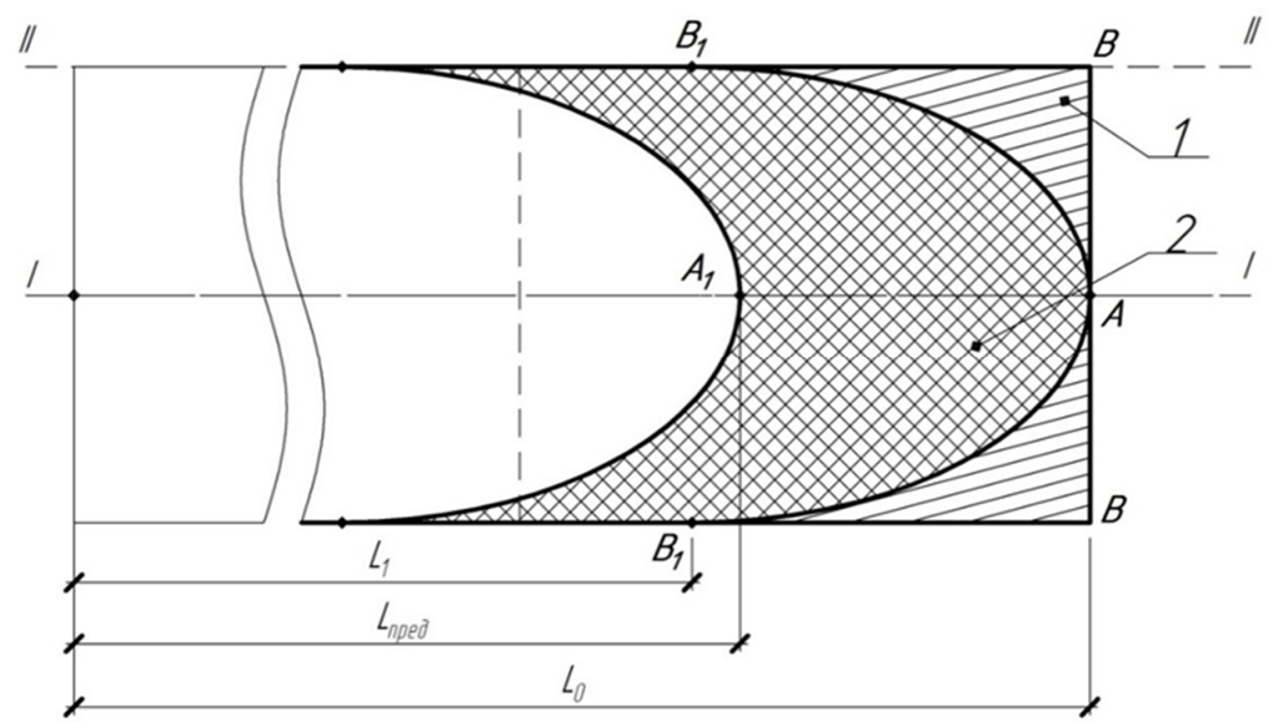

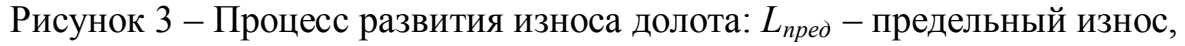
1 - протекание первого этапа износа, 2 - протекание второго этапа износа, I-I, II-II - контрольные сечения

Figure 3 - The process of development of bit wear: Lnped-limit wear, 1-the course of the first stage of wear, 2-the course of the second stage of wear, I-I, II-II-control sections

Моделирование процесса износа долот чизельного плуга становится затруднительным, так как в зависимости от выбранного поля, а зачастую и в пределах одного поля почва имеет различные физико-механические свойства и гранулометрический со- 
став. Разнятся в зависимости от типа почв и количество зафиксированных в них абразивных частиц, число которых может меняться от 37 до $77 \%$, а также разнообразным выбором представленных на данный момент материалов, из которых изготавливаются рабочие органы чизельных плугов.

Предложено в нашей задаче отбросить количественную сторону (она нам неизвестна) и решать её качественно: обосновать критерий формирования геометрической формы рабочей поверхности органа при взаимодействии с почвой, не рассматривая с количественной стороны величину износа. В этом случае мы сможем сделать допущения, существенно упрощающие объект исследования.

Износ долота предложено разделить на два этапа: на первом этапе формируется геометрия носовой части долота, обеспечивающая наименьшие затраты энергии на перемещение долота чизельного плуга в почве; на втором этапе происходит перемещение полученной геометрической фигуры острия долота параллельно продольной оси долота до полного износа (рисунок 3 ).

Частица почвы способна перемещаться по поверхности с минимальными затратами энергии, если нормальная реакция такой поверхности стремится к нулю с постоянной силой $R$ из точки $A$ в $B$, не учитывая массу (рисунок 4).

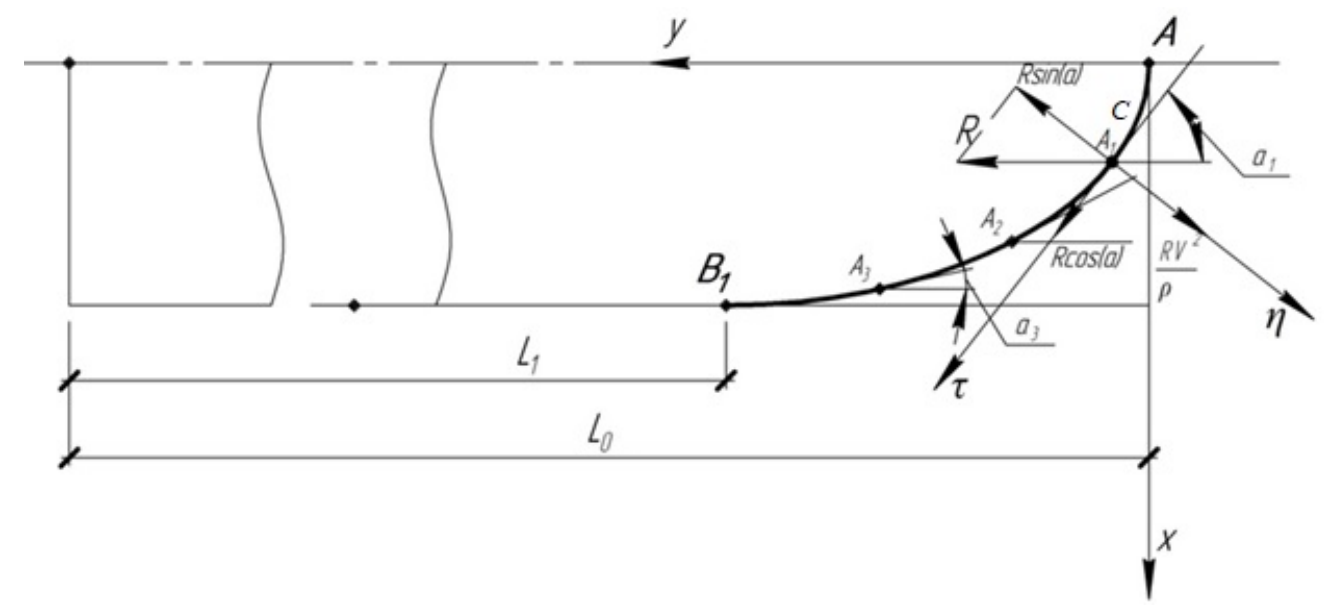

Рисунок 4 - Силы, возникающие при перемещении частицы почвы по параболической поверхности лезвия долота

Figure 4 - Forces that occur when a soil particle moves along the parabolic surface of the chisel blade

Предположим, что частица находится в точке С в момент $t=t_{l}$. Тогда уравнение движения в проекциях на ось $\tau$ и $n$ примут вид:

$$
\begin{gathered}
\frac{d v}{d t}=R \cos \alpha \\
N=0=R \sin \alpha-R \frac{v^{2}}{\rho}=\sin \alpha-\frac{v^{2}}{\rho} \geq 0
\end{gathered}
$$

Сделаем анализ первого уравнения, приняв во внимание, что:

$$
\cos \alpha=\frac{d y}{d s},
$$

где $S$ - расстояние от начального положения до точки $C$, получим: 
Разделив, имеем:

$$
\frac{d v}{d t}=R \frac{d y}{d s}
$$

$$
\frac{d v d s}{d t}=R d s
$$

Приняв $\frac{d s}{d t}=v$, имеем:

$$
v d v=R d y
$$

Проинтегрируем обе части:

$$
\int_{v_{0}}^{v} v d v=R \int_{0}^{y} d y,
$$

начальные условия: при $t=0 ; v=v_{0} ; y=y_{0}$, имеем:

$$
v^{2}=2 R y+v_{0}^{2}-2 R_{y o},
$$

или

$$
v^{2}=v_{0}^{2}+2 R\left(y-y_{o}\right) .
$$

Второе уравнение:

$$
v^{2}=\rho \sin \alpha,
$$

принимая во внимание, что $\sin \alpha=\frac{d x}{d s}$, имеем:

$$
v^{2}=\rho \frac{d x}{d s}
$$

Радиус кривизны траектории $\rho$ представим как:

$$
\rho=\frac{d s}{d \alpha},
$$

с этим учетом выражение 5 имеет вид:

$$
v^{2}=\frac{d s}{d \alpha} \cdot \frac{d x}{d s}=\frac{d x}{d \alpha} .
$$

После некоторых преобразований получим:

$$
y=a x^{2}-b x+c .
$$

Таким образом, искомая траектория движения частицы почвы по поверхности режущей части долота представляет собой параболу.

Износ реальных образцов (рисунок 5) доказывает теоретический расчет траектории, формирование параболы в носовой части происходит с концов лезвия образца, при этом вершиной параболы является продольная ось симметрии долота чизельного плуга, что нашло подтверждение в расчетных зависимостях. 


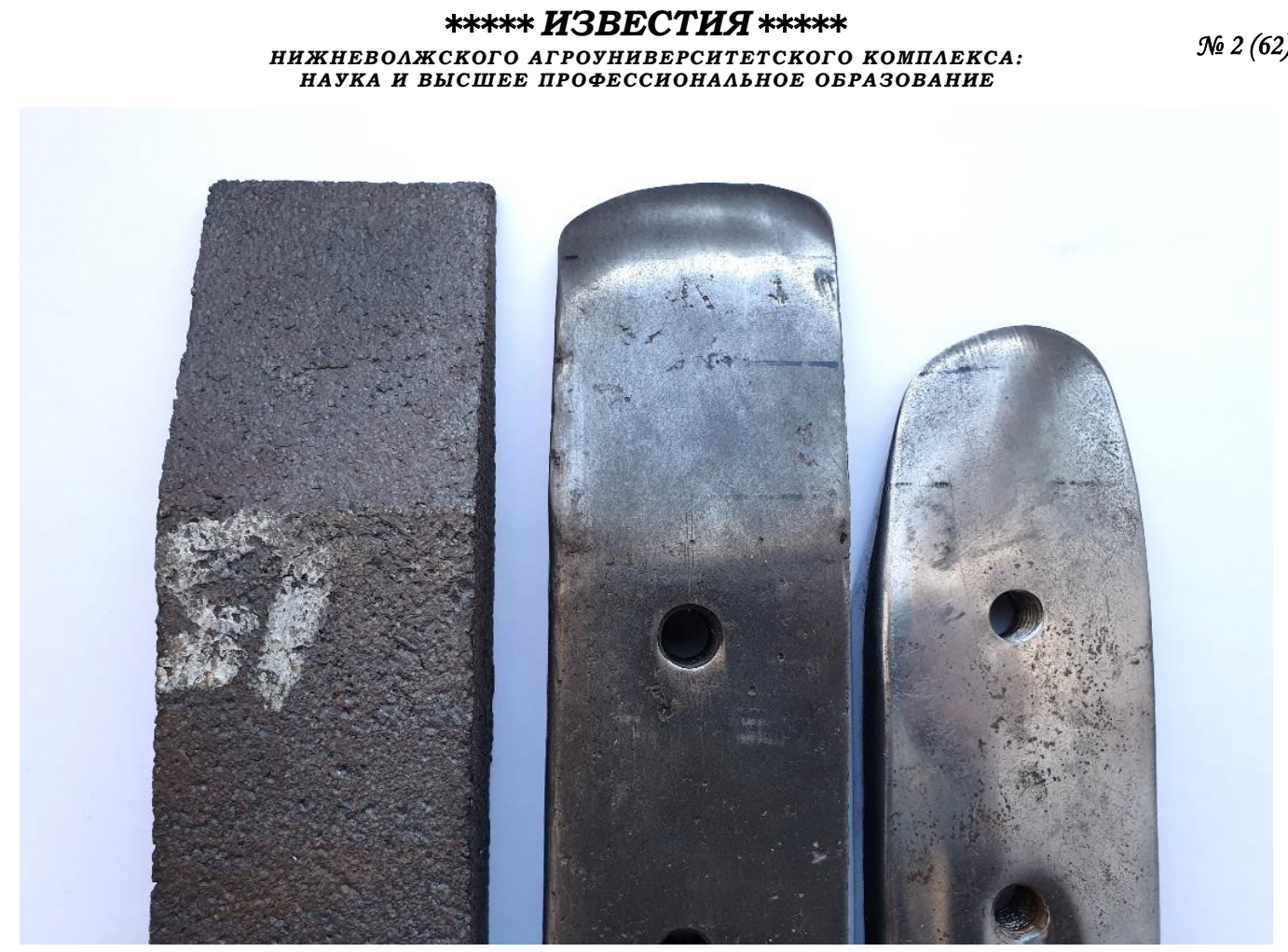

Рисунок 5 - Формирование носовой части долот чизельного плуга: первый слева в состоянии после отливки, ВЧ 50; второй - наработка 100 га ВЧ 50 (первый этап износа); третий слева - наработка 30 га, Сталь 45 (второй этап износа)

Figure 5 - Formation of the nose of the chisel chisel plow: the first on the left in the state after casting, RF 50, the second - time 100 ha HF 50 (the first stage of wear); the third left accumulation of 30 hectares, 45 Steel (second stage wear)

Выводы. Экспериментальные исследования показали, что независимо от материала, из которого изготовлены долота чизельных орудий, картины формирования геометрии износа рабочих поверхностей подчиняются единой логике. Первый этап - формирование геометрии носовой части, второй этап - поступательное перемещение полученного сечения режущей части. Предельный технический ресурс долота чизельного плуга контролируется линейным износом сечения I-I. Зная значение предельного износа, на любом этапе работ и наработке определяем линейный размер сечения $I-I$ и из условия подобия определяем технический ресурс долота чизельного плуга.

\section{Библиографический список}

1. Дорошенко В. С., Гнатуш В. А. Мировой рынок литья чугуна с шаровидным графитом. Состояние и перспективы развития // Вестник арматуростроителя. 2017. № 5. С. 112-119.

2. Костылева Л. В., Гапич Д. С., Моторин В. А. Комплексное влияние химического состава чугуна на структуру отбеленного слоя долота чизельного плуга // Известия Нижневолжского агроуниверситетского комплекса: Наука и высшее профессиональное образование. 2016. № 2. С. 221-228.

3. Сильман Г. И., Макаренко К. В., Зенцова Е. А. Бейнитный высокопрочный чугун с шаровидным графитом // Металловедение и термическая обработка металлов. 2013. № 4. С. 3-8.

4. Формирование износостойких зонально-распределенных структур деталей орудий для почвообработки из высокопрочного чугуна / В. А. Моторин, Д. С. Гапич, Л. В. Костылева, А. Е. Новиков // Известия Нижневолжского агроуниверситетского комплекса: Наука и высшее профессиональное образование. 2018. № 4. С. 269-276.

5. Al-Sayed S. R., Elshazli A. M., Hussein A. H. A. Laser surface hardening of Ni-hard white cast iron // Metals. 2020. V. 10(6). I. 795. P. 1-19. 
6. An investigation on the stability of austenite in Austempered Ductile Cast Iron (ADI) / S. Panneerselvam, C. J. Martis, S. K. Putatunda, J. M. Boileau // Materials Science and Engineering . 2015. V. 626. P. 237-246.

7. Composition and Tribological Properties of Hardened Cutting Blades of Tillage Machines under Abrasive Deterioration / A. E. Novikov, V. A. Motorin, M. I. Lamskova, M. I. Filimonov // Journal of Friction and Wear. 2018. Vol. 39. No. 2. P. 158-163.

8. Effect of the starting microstructure in the formation of austenite at the intercritical range in ductile iron alloyed with nickel and copper / H. D. Machado, R. Aristizabal-Sierra, C. Garcia-Mateo, I. Toda-Caraballo // International Journal of Metalcasting. 2020. V. 14 (3). P. 836-845.

9. Influence of cooling rate on the microstructure and properties of a new wear resistant carbidic austempered ductile iron (CADI) / Y. Ch. Peng, H. J. Jin, J. H. Liu, G. L. Li // Materials Characterization. 2012. Vol. 72. P. 53-58.

10. Influence of solidification conditions on the microstructure of laser-surface-melted ductile cast iron / D. Janicki, J. Górka, W. Kwaśny, W. Pakiela, K. Matus // Materials. 2020. V. 13 (5). P. 1174.

11. Neutron diffraction monitoring of ductile cast iron under cyclic tension-compression / S. Harjo, S. Kubota, W. Gong, T. Kawasaki, S. Gao // Acta Materialia. 2020. V. 196. P. 584-594.

12. Non-single bionic coupling model for thermal fatigue and wear resistance of gray cast iron drum brake / D. Yu, T. Zhou, H. Zhou, H. Bo, H. Lu // Optics and Laser Technology. 2019. V. 111. P. 781-788.

13. Probabilistic Low Cycle Fatigue criterion for nodular cast-irons / F. Szmytka, E. Charkaluk, A. Constantinescu, P. Osmond // International Journal of Fatigue. 2020. V. 139. P. 105701.

14. Pyndak V. I., Novikov A. E. Tribotechnical and Energy Assessment of Parts of Working Members of Cultivating Machines After Carburizing and Laser Hardening // Metal Science and Heat Treatment. 2016. Vol. 58. No. 3-4. P. 226-230.

15. Surface alloying of gray cast iron with chromium by high current pulsed electron beam treatment / C. Li, Q. Guan, J. Cai, P. Lv, Y. Jin // Materials Research Express. 2018. V. 5. I. 6. No. 066518 .

Conclusions. The working capacity of the plow body is determined by the amount of wear on the plowshare. this value has a significant impact on the energy and quality indicators of the plow unit. A promising technology for manufacturing plowshares is their casting from high-strength metal, with hardening of the cutting edge of the plowshare with a material from high-alloy alloys. The alloyed layer of the ploughshare obtained by casting has a significantly greater thickness and increased hardness compared to the deposited layer, which allows you to increase the product life. The resource of experimental ploughshares is almost three times higher than the resource of its serial counterpart and is 12 hectares of operating time per case, while the same indicator for a serial ploughshare is only 4.7 hectares.

\section{References}

1. Doroshenko V. S., Gnatush V. A. World market for nodular cast iron. State and development prospects // Bulletin of the valve-constructor. 2017. No. 5. P. 112-119.

2. Kostyleva L. V., Gapich D. S., Motorin V. A. Complex influence of the chemical composition of cast iron on the structure of the bleached layer of a chisel plow chisel // News of the Nizhnevolzhsky agro-university complex: Science and higher professional education. 2016. No. 2. P. 221-228.

3. Silman G. I., Makarenko K. V., Zentsova E. A. Beinitny high-strength cast iron with spherical graphite // Metallurgy and heat treatment of metals. 2013. No. 4. P. 3-8.

4. Formation of wear-resistant zonal-distributed structures of details of tools for soil treatment from high-strength cast iron / V. A. Motorin, D. S. Gapich, L. V. Kostyleva, A. E. Novikov // Izvestiya nizhnevolzhskogo agrouniversitetskogo kompleksa: Nauka I vyshe vocational education. 2018. No. 4. P. 269-276. 
5. Al-Sayed S. R., Elshazli A. M., Hussein A. H. A. Laser surface hardening of Ni-hard white cast iron // Metals. 2020. V. 10(6). I. 795. P. 1-19.

6. An investigation on the stability of austenite in Austempered Ductile Cast Iron (ADI) / S. Panneerselvam, C. J. Martis, S. K. Putatunda, J. M. Boileau // Materials Science and Engineering . 2015. V. 626. P. 237-246.

7. Composition and Tribological Properties of Hardened Cutting Blades of Tillage Machines under Abrasive Deterioration / A. E. Novikov, V. A. Motorin, M. I. Lamskova, M. I. Filimonov // Journal of Friction and Wear. 2018. Vol. 39. No. 2. P. 158-163.

8. Effect of the starting microstructure in the formation of austenite at the intercritical range in ductile iron alloyed with nickel and copper / H. D. Machado, R. Aristizabal-Sierra, C. Garcia-Mateo, I. Toda-Caraballo // International Journal of Metalcasting. 2020. V. 14 (3). P. 836-845.

9. Influence of cooling rate on the microstructure and properties of a new wear resistant carbidic austempered ductile iron (CADI) / Y. Ch. Peng, H. J. Jin, J. H. Liu, G. L. Li // Materials Characterization. 2012. Vol. 72. P. 53-58.

10. Influence of solidification conditions on the microstructure of laser-surface-melted ductile cast iron / D. Janicki, J. Górka, W. Kwaśny, W. Pakiela, K. Matus // Materials. 2020. V. 13 (5). P. 1174.

11. Neutron diffraction monitoring of ductile cast iron under cyclic tension-compression / S. Harjo, S. Kubota, W. Gong, T. Kawasaki, S. Gao // Acta Materialia. 2020. V. 196. P. 584-594.

12. Non-single bionic coupling model for thermal fatigue and wear resistance of gray cast iron drum brake / D. Yu, T. Zhou, H. Zhou, H. Bo, H. Lu // Optics and Laser Technology. 2019. V. 111. P. 781-788.

13. Probabilistic Low Cycle Fatigue criterion for nodular cast-irons / F. Szmytka, E. Charkaluk, A. Constantinescu, P. Osmond // International Journal of Fatigue. 2020. V. 139. P. 105701.

14. Pyndak V. I., Novikov A. E. Tribotechnical and Energy Assessment of Parts of Working Members of Cultivating Machines After Carburizing and Laser Hardening // Metal Science and Heat Treatment. 2016. Vol. 58. No. 3-4. P. 226-230.

15. Surface alloying of gray cast iron with chromium by high current pulsed electron beam treatment / C. Li, Q. Guan, J. Cai, P. Lv, Y. Jin // Materials Research Express. 2018. V. 5. I. 6. No. 066518 .

\section{Authors Information}

Gapich Dmitry Sergeevich, head of the Department "Operation and technical service of machines in agriculture», Volgograd State Agrarian University (400002, Volgograd, pr. Universitetsky, 26), Associate Professor, e-mail: gds-08@mail.ru.

Motorin Vadim Andreevich, associate Professor of the Department "Operation and technical service of machines in agriculture», Volgograd State Agrarian University (400002, Volgograd, pr. Universitetsky, 26), Candidate of Technical Sciences, Associate Professor, e-mail: vmotorin001@yandex.ru.

Oleynikov Roman Nikolaevich, post-graduate student of the Department "Operation and technical service of machines in agriculture», Volgograd State Agrarian University (400002, Volgograd, pr. Universitetsky, 26), e-mail: olejnikov.rom@yandex.ru.

\section{Информация об авторах}

Гапич Дмитрий Сергеевич, заведующий кафедрой «Эксплуатация и технический сервис машин в АПК» ФГБОУ ВО «Волгоградский государственный аграрный университет» (400002, г. Волгоград, пр-т. Университетский, 26), доктор технических наук, доцент, e-mail: gds-08@mail.ru.

Моторин Вадим Андреевич, доцент кафедры «Эксплуатация и технический сервис машин в АПК» ФГБОУ ВО «Волгоградский государственный аграрный университет» (400002, г. Волгоград, пр-т. Университетский, 26), кандидат технических наук, доцент, e-mail: vmotorin001@yandex.ru

Олейников Роман Николаевич, аспирант кафедры «Эксплуатация и технический сервис машин в АПК» ФГБОУ ВО «Волгоградский государственный аграрный университет» (400002, г. Волгоград, пр-т. Университетский, 26). e-mail: olejnikov.rom@yandex.ru. 